\title{
Application of T-tests for Horticulture Data (Watermelon, Mangoes) with an Example Problems and Solutions
}

\author{
V. Sekhar ${ }^{*}$, K. Umakrishna ${ }^{1}$ and V. Srinivasa Rao ${ }^{2}$
}

${ }^{1}$ Department of Statistics, College of Horticulture, Venkataramannagudem, Dr. YSR Horticultural University, West Godavari (District), Andhra Pradesh (State), India

${ }^{2}$ Department of Statistics, Agricultural College, Bapatla, Acharya NG Ranga Agricultural University, Guntur (District), Andhra Pradesh (State), India

*Corresponding author

\section{A B S T R A C T}

\section{Keywords}

One-sample t-test, Two-sample t-test, Paired t-test, Null Hypothesis, Alternative Hypothesis

Article Info

Accepted:

10 February 2019

Available Online:

10 March 2019

\section{Introduction}

William Sealy Gosset, who developed the "tstatistic" and published it under the pseudonym of "Student" in 1908 (1).

\section{Assumptions and conditions of t-test}

The sample is drawn from normal population All observations in the sample are independent

Sample size lies between 5 and 30

The hypothetical value $\mu_{0}=\mu$ is a correct value of population mean

The sample values are correctly measured and recorded $(2,3)$

\section{Materials and Methods}

\section{One sample t-test}

\section{Example problem 1}

The weights of 14 watermelons in a farm in kgs are 6.4, 8.5, 5.5, 7.5, 6.5, 4.5, 5.3, 2.5, 2.4, 4.5, 5.5, 3.5, 3.2, and 4.2. As per old 
records, the mean weight of watermelon of that farm is $6 \mathrm{~kg}$. Test for the significance.

Sol

Null Hypothesis $\left(H_{0}\right)$ : There is no significant difference between mean weight and sample mean of watermelons

i.e. ${ }^{H_{0} \Sigma} \mu=\mu_{0}$

Alternative Hypothesis $\left(H_{1}\right)$ : There is significant difference between mean weight and sample mean of watermelons

i.e. ${ }^{H_{1} \frac{5}{5}} \mu \neq \mu_{0}$

Statistic $(2,4,5)$

$t=\frac{|\bar{x}-\mu|}{\frac{s}{\sqrt{n}}}$

Where ${ }^{\bar{x}}$ is sample mean

$\mu$ is population mean

$s$ is sample standard deviation

$\mathrm{n}$ is number of observation in $\mathrm{X}$ data

\begin{tabular}{|c|c|}
\hline $\mathbf{X}_{\mathbf{i}}$ & $\overline{X_{i}^{2}}$ \\
\hline 6.4 & 40.96 \\
\hline 8.5 & 72.25 \\
\hline 5.5 & 30.25 \\
\hline 7.5 & 56.25 \\
\hline 6.5 & 42.25 \\
\hline 4.5 & 20.25 \\
\hline 5.3 & 28.09 \\
\hline 2.5 & 6.25 \\
\hline 2.4 & 5.76 \\
\hline 4.5 & 20.25 \\
\hline 5.5 & 30.25 \\
\hline 3.5 & 12.25 \\
\hline 3.2 & 10.24 \\
\hline 4.2 & 17.64 \\
\hline$\sum X_{i}={ }_{70}$ & $\sum X_{i}^{2}=392.94$ \\
\hline
\end{tabular}

Where

$\mu_{\text {is population mean }}=6 \mathrm{~kg}$

$\mathrm{n}$ is number of samples $=14$

$\bar{X}_{\text {is sample mean }}=\frac{\sum x_{\bar{i}}}{n}=\frac{70}{14}=5$

$s$ is sample standard deviation = $\sqrt{\frac{1}{n-1}\left[\sum X_{i}^{2}-\frac{\left(\sum X_{i}\right)^{2}}{n}\right]}$

$=\sqrt{\frac{1}{14-1}\left[392.94-\frac{(70)^{2}}{14}\right]}=\sqrt{\frac{1}{13}\left[392.94-\frac{4900}{14}\right]}$

$=\sqrt{\frac{1}{13}[392.94-350]}$

$=\sqrt{\frac{42.94}{13}}=\sqrt{3.3031}=1.8174$

$t=\frac{|\bar{x}-\mu|}{\frac{s}{\sqrt[3]{n}}}=\frac{|5-6|}{\frac{1.8174}{\sqrt{14}}}=\frac{1}{0.4857}=2.0589$

\section{NS}

Two Sample $\mathrm{t}$ - test

\section{Example problem 2}

The yields of mangoes in Uttar Pradesh(X) and Andhra Pradesh(Y) in tonnes/hector at the age of mango trees range from 15-20 years are as follows

\begin{tabular}{|l|l|l|l|l|l|l|l|l|l|}
\hline U.P(X) & 15 & 17 & 20 & 16 & 15 & 20 & 16 & 15 & \\
\hline A.P(Y) & 17 & 18 & 20 & 15 & 16 & 18 & 15 & 16 & 15 \\
\hline
\end{tabular}

Test whether there is significant difference in yields between two states with respect to mangoes

Sol

- In two sample t - test, sample sizes may or may not be equal

- Samples are not related 
$H_{0^{*}}$ There is no significant difference in yields between two states with respect to mangoes

i.e. ${ }^{H_{0}: \mu_{1}=\mu_{2}}$

$H_{1^{*}}$ There is significant difference in yields between two states with respect to mangoes

i.e. ${ }^{H_{1}: \mu_{1}} \neq \mu_{2}$

\section{Statistic}

$t=\frac{|\bar{x}-\bar{x}|}{\sqrt{s^{2}\left(\frac{x}{m_{1}}+\frac{x}{m_{2}}\right)}}$

Where $\bar{x}_{\text {is first sample mean }}$

$\bar{y}_{\text {is second sample mean }}$

$s^{2}$ is Pooled variance or combined variance

$s^{2}=\frac{\left(n_{1}-1\right) s_{1}^{x}+\left(n_{2}-1\right) s_{2}^{x}}{n_{1}+n_{2}-2}$

$n_{1}$ is first sample size

$n_{2}$ is second sample size

$s_{1}^{2}$ is first sample variance

$s_{1}^{2}=\frac{1}{n_{1}-1}\left[\sum X_{i}^{2}-\frac{\left(\sum X_{i}\right)^{2}}{n_{1}}\right]$

$s_{2}^{2}$ is second sample variance

$$
s_{2}^{2}=\frac{1}{n_{\mathrm{z}}-1}\left[\sum Y_{\bar{i}}^{2}-\frac{\left(\Sigma Y_{\mathrm{i}}\right)^{\mathrm{x}}}{n_{\mathrm{z}}}\right]
$$

\begin{tabular}{|l|l|l|l|}
\hline $\mathbf{X}_{\mathbf{i}}$ & $\mathbf{Y}_{\mathbf{i}}$ & $\boldsymbol{X}_{\boldsymbol{i}}^{\mathbf{2}}$ & $\boldsymbol{Y}_{\boldsymbol{i}}^{\mathbf{2}}$ \\
\hline 15 & 17 & 225 & 289 \\
\hline 17 & 18 & 289 & 324 \\
\hline 20 & 20 & 400 & 400 \\
\hline 16 & 15 & 256 & 225 \\
\hline 15 & 16 & 225 & 256 \\
\hline 20 & 18 & 400 & 324 \\
\hline 16 & 15 & 256 & 225 \\
\hline 15 & 16 & 225 & 256 \\
\hline-- & 15 & -- & 225 \\
\hline$\sum X_{i}=134$ & $\sum Y_{i}=150$ & $\sum \boldsymbol{X}_{\boldsymbol{i}}^{\mathbf{2}}={ }_{\mathbf{2 2 7 6}}$ & $\sum \boldsymbol{X}_{\boldsymbol{i}}^{\mathbf{2}}={ }_{\mathbf{2 5 2 4}}$ \\
\hline
\end{tabular}

$\bar{x}=\frac{\sum X_{\bar{i}}}{n_{1}}=\frac{134}{8}=16.75$

$\bar{y}=\frac{\sum Y_{i}}{n_{2}}=\frac{150}{9}=16.6667$

$s_{1}^{2}=\frac{1}{n_{1}-1}\left[\sum X_{i}^{2}-\frac{\left(\sum X_{i}\right)^{2}}{n_{1}}\right]=\frac{1}{8-1}\left[2276-\frac{(134)^{2}}{8}\right]=\frac{1}{8-1}[2276-2244.5]$

$=\frac{1}{8-1}[31.5]=\frac{31.5}{7}=4.5$

$s_{2}^{2}=\frac{1}{n_{2}-1}\left[\sum Y_{i}^{2}-\frac{\left(\sum Y_{i}\right)^{2}}{n_{2}}\right]=\frac{1}{9-1}\left[2524-\frac{(150)^{2}}{9}\right]=\frac{1}{9-1}[2524-2500]$

$=\frac{1}{9-1}[24]=\frac{24.0}{8}=3.0$

$s^{2}=\frac{\left(n_{1}-1\right) s_{1}^{2}+\left(n_{2}-1\right) s_{2}^{2}}{n_{1}+n_{2}-2}=\frac{(8-1) 4.5+(9-1) 3.0}{8+9-2}=\frac{(7) 4.5+(8) 3.0}{15}=\frac{55.5}{15}=3.7$

$t=\frac{|16.75-16.6667|}{\sqrt{3.7\left(\frac{1}{8}+\frac{1}{9}\right)}}=\frac{|16.75-16.6667|}{\sqrt{3.7\left(\frac{1}{8}+\frac{1}{9}\right)}}=\frac{|0.0833|}{\sqrt{3.7\left(\frac{1}{8}+\frac{1}{9}\right)}}=\frac{|0.0833|}{\sqrt{3.7(0.2361)}}$

$=\frac{|0.0833|}{\sqrt{0.8736}}=\frac{|0.0833|}{0.9347}=0.0892 \mathrm{NS}$

\section{Paired t-test}

\section{Example problem 3}

The following are the yields in tonnes/hector obtained by 10 fields of mango trees at the age from 10-15 years and 15-20 are as follows

\begin{tabular}{|c|c|c|c|c|c|c|c|c|c|c|}
\hline Field No. & 1 & 2 & 3 & 4 & 5 & 6 & 7 & 8 & 9 & 10 \\
\hline $\begin{array}{l}\text { Yield of } \\
\text { mangoes in } \\
\text { tonnes/ha at } \\
\text { theage of } 10- \\
15 \text { years of } \\
\text { mango trees }\end{array}$ & 10 & 12 & 12 & 10 & 9 & 8 & 10 & 11 & 12 & 10 \\
\hline $\begin{array}{l}\text { Yield of } \\
\text { mangoes in } \\
\text { tonnes/ha at } \\
\text { the age of } 15- \\
20 \text { years of } \\
\text { mango trees }\end{array}$ & 17 & 18 & 20 & 15 & 16 & 18 & 15 & 16 & 15 & 18 \\
\hline
\end{tabular}


Is there any evidence that age of trees benefited the farmers significantly?

Sol

- In paired $\mathrm{t}$ - test, sample sizes should be equal i.e., $\mathrm{n}_{1}=\mathrm{n}_{2}=\mathrm{n}$

- Samples are related i.e., dependent on each other

$H_{0}{ }^{*}$ There is no significant difference among 10 mango fields with respect to yields at two different age periods

$H_{0}: \mu_{d}=0$

$H_{1^{*}}$ There is significant difference among 10 mango fields with respect to yields at two different age periods

$H_{1}: \mu_{d} \neq 0$

Statistic

$t=\frac{|\bar{d}|}{\frac{s_{d}}{\sqrt{n}}}$

Where $\bar{d}_{\text {is mean }}$

$s_{d}$ is standard deviation

$\mathrm{n}$ is number of samples

\begin{tabular}{|l|l|l|l|}
\hline $\mathbf{X}_{\mathbf{i}}$ & $\mathbf{Y}_{\mathbf{i}}$ & $\mathbf{d}_{\mathbf{i}}=\mathbf{X}_{\mathbf{i}}-\mathbf{Y}_{\mathbf{i}}$ & $\boldsymbol{d}_{\boldsymbol{i}}^{2}$ \\
\hline 10 & 17 & -7 & 49 \\
\hline 12 & 18 & -6 & 36 \\
\hline 12 & 20 & -8 & 64 \\
\hline 10 & 15 & -5 & 25 \\
\hline 9 & 16 & -7 & 49 \\
\hline 8 & 18 & -10 & 100 \\
\hline 10 & 15 & -5 & 25 \\
\hline 11 & 16 & -5 & 25 \\
\hline 12 & 15 & -3 & 9 \\
\hline 10 & 18 & -8 & 64 \\
\hline & & $\sum \boldsymbol{d}_{\boldsymbol{i}}=\mathbf{- 6 4}$ & $\sum \boldsymbol{d}_{\boldsymbol{i}}^{\mathbf{2}}={ }_{\mathbf{4 4 6}}$ \\
\hline
\end{tabular}

Where

$\mathrm{n}$ is number of samples $=10$

$\bar{d}_{\text {is sample mean }}=\frac{\sum d_{i}}{n}=\frac{-64}{10}=-6.4$

$s_{d}$ is sample standard deviation = $\sqrt{\frac{1}{n-1}\left[\sum d_{i}^{2}-\frac{\left(\sum d_{i}\right)^{2}}{n}\right]}$

$=\sqrt{\frac{1}{10-1}\left[446-\frac{(-64)^{2}}{10}\right]}=\sqrt{\frac{1}{9}\left[446-\frac{4096}{10}\right]}$

$=\sqrt{\frac{1}{9}[446-409.6]}$

$=\sqrt{\frac{36.4}{9}}=\sqrt{4.0444}=2.0111$

$t=\frac{|\bar{d}|}{\frac{s_{d}}{\sqrt{n}}}=\frac{|-6.4|}{\frac{2.0111}{\sqrt{10}}}=\frac{6.4}{\frac{2.0111}{3.1623}}=\frac{6.4}{0.6360}=10.0634$

\section{Results and Discussion}

Conclusion and interpretation for one sample t-test

As t-calculated value $(2.0589)<\mathrm{t}$-tabulated value with $(n-1)=(14-1)=13$ degrees of freedom is $2.1604(5 \%$ LOS) and $3.0123(1 \%$ LOS) null hypotheses accepted. i.e., There is no significant difference between mean weight and sample mean of watermelons.

\section{Conclusion and interpretation for two sample t-test}

As t-calculated value $(0.0892)<\mathrm{t}$-tabulated value with $\left(\mathrm{n}_{1}+\mathrm{n}_{2}-2\right)=(8+9-2)=15$ degrees of freedom is $2.1314(5 \%$ LOS) and 2.9467 (1\% LOS) null hypotheses accepted. i.e., There is no significant difference in yields between two states with respect to mangoes 
Conclusion and interpretation for Paired t-test are as follows:

As t-calculated value (10.0634) > t-tabulated value with $(n-1)=(10-1)=9$ degrees of freedom 2.2622(5\% LOS) and $3.2498(1 \%$ LOS). So, the null hypothesis is rejected. i.e., There is highly significant difference among 10 mango fields with respect to yields at two different age periods of mango trees.

\section{References}

1. Statistics for Agricultural Sciences- G. Nageswara Rao, BS Publications, Hyderabad (Second Edition), 2007.
2. Programmed Statistics (QuestionsAnswers) $2^{\text {nd }}$ Edition- B. L. Agarwal, New Age International Publishing Limited, New Delhi, 2009.

3. A text Book of Agricultural StatisticsR. Rangaswamy, New Age International Publishing Limited, Hyderabad, 2010.

4. Practical manual of STCA-101 (for class use only)- Dr. V. Srinivasa Rao and R. Srinivasulu, Agricultural College, Bapatla, 2013.

5. Fundamentals of Mathematics and Statistics - S. C. Gupta and V. K. Kapoor, Sultan Chand \& Sons, Delhi, 2014.

\section{How to cite this article:}

Sekhar, V., K. Umakrishna and Srinivasa Rao, V. 2019. Application of T-tests for Horticulture Data (Watermelon, Mangoes) with an Example Problems and Solutions. Int.J.Curr.Microbiol.App.Sci. 8(03): 960-964. doi: https://doi.org/10.20546/ijcmas.2019.803.115 